\title{
The correlation between ferritin level and cardiac dysfunction in patients with thalassemia
}

\author{
Fajar Subroto, MD; Bulan Ginting Munthe, MD; Najib Advani, MD; Agus Firmansyah, MD, PhD
}

\begin{abstract}
Background Patients with b-thalassemia major, long-term transfusion, extravasal hemolytic, and increased intestinal absorption of iron result in systemic iron overload, which may accumulate in myocardium causing cardiac dysfunctions. Congestive heart failure usually develops in adolescence or early adult years, and patient usually dies within 1 year after the onset of symptoms. Therefore, it is important to detect early signs of cardiac dysfunction in patient with thalassemia.

Objective This study aimed to assess the correlation between ferritin level and cardiac dysfunction in patients with thalassemia. Methods A cross sectional study was conducted on 62 b-thalassemic patients (34 males and 28 females) with age ranging from 3.5 to 23 years. They received $3,150-94,985 \mathrm{~mL}$ of blood; with the serum ferritin level of $812.2-12,175 \mathrm{ng} / \mathrm{mL}$. Each patient underwent laboratory examinations and clinical cardiac evaluation with ECG and echocardiography.

Results Cumulative blood transfusions correlated well with the serum ferritin values $(p=0.001)$. The serum ferritin level did not show correlation with deferoxamine (DFO) treatment. ECG examination revealed 5 patients $(8.1 \%)$ with dysrhythmia, $\mathrm{LVH}$, and heart block grade II and I. Echocardiography examination showed 18 patients $(29 \%)$ with systolic or diastolic dysfunction. There was no correlation between the serum ferritin level and cardiac dysfunctions $(p=0.640)$. The serum ferritin prediction value against cardiac dysfunctions could not be established.

Conclusion There was no correlation between serum ferritin levels with cardiac dysfunctions. In detecting cardiac dysfunctions in thalassemic patients, echocardiography was more sensitive than ECG [Paediatr Indones 2003;43:24-27].
\end{abstract}

Keywords: th alassemia, iron overload, ferritin, cardiac dysfunctions, ECG, echocardiography.

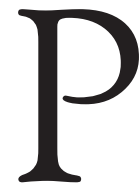
atients with $b$-thalassemia major, long-term transfusion, extravasal hemolysis, and increased intestinal absorption of iron result in systemic iron overload. ${ }^{1}$ A large excessive of steadily iron storage accumulation that will progressively damage the organs is called hemochromatosis. ${ }^{2-6}$ The deposition of iron in myocardium causes cardiac dysfunctions. When cardiac impairment caused by iron deposition is severe enough to be clinically obvious, the disease is advanced and the subsequent survival is brief, congestive heart failure develops usually in adolescence or early adult years, and patient usually dies within 1 year after the onset of symptoms. ${ }^{7,8}$ Therefore, it is important to detect early signs of cardiac dysfunction in patient with thalassemia.

The serum ferritin concentration correlates well with the deposited iron in the tissue. Measurement of serum ferritin has been a valuable tool for evaluating iron status clinically and has been used as a marker in many screening studies. ${ }^{9-11}$ ECG and roentgenography are relatively insensitive in detecting cardiac dysfunction before the onset of clinically apparent disease. Echocardiography permits detection of anatomic and functional abnormalities before the onset of abnormalities detectable with ECG and rontgenography. ${ }^{12,13}$ This study aimed to assess the correlation between ferritin level and cardiac dysfunction in patients with thalassemia.

From the Division of Hematology and Cardiology, Department of Child Health, Medical School, University of Indonesia-Cipto Mangunkusumo Hospital, Jakarta.

Reprint requests to: Fajar Subroto, MD, Department of Child Health, Medical School, University of Indonesia, Cipto Mangunkusumo Hospital, Jakarta, Indonesia. Tel. 62-21-390 7740, Fax, 62-21-390 7743. 
Fajar Subroto et al: Ferritin level and cardiac dysfunction in thalassemia

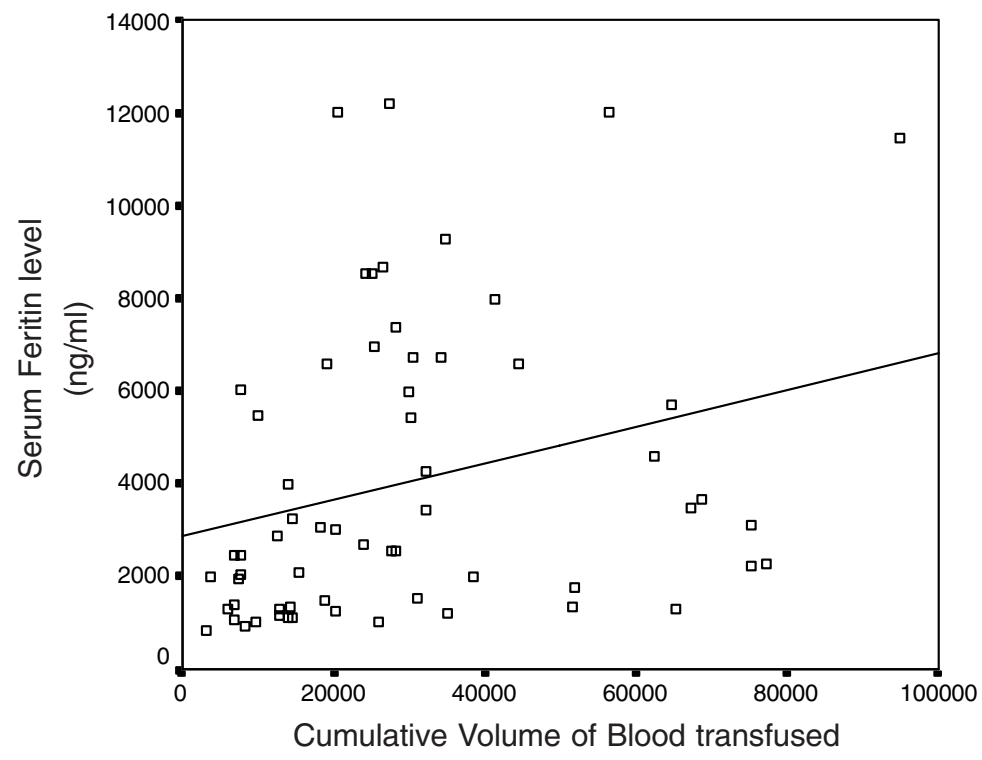

Figure 1. Correlation between serum ferritin with cumulative blood transfusions

\section{Methods}

Sixty two consecutive patients ( 34 males, 28 females) with b-thalassemia major were studied from FebruaryNovember 2001. All patients regularly visited the Thalassemia Center, Department of Child Health, Cipto Mangunkusumo Hospital. The inclusion criteria were absence of cardiac symptoms or clinically apparent heart disease and had received a minimal of 10 units transfusion. None of the patients was treated with cardioactive medications. The mean of age was 11.5 (range 3.5-23; SD 5.2) years. Transfusion therapy had been started at the age range of 2 month to 10 years. At the time of the cardiac evaluation done, cumulative transfusion loads varied from 3.150 to $94.985 \mathrm{~mL}$, with ferritin level of $812.2-12.175 \mathrm{ng} /$ $\mathrm{mL}$. Eleven patients had iron chelation treatment with deferoxamine with optimal compliance, while the remaining patients had sporadic chelation or have not had deferoxamine treatment at all. Each patient underwent laboratory examinations and clinical cardiac evaluation with ECG and echocardiography.

\section{Results}

Electrocardiography examinations showed cardiac dysrhythm occurring in two patients and $1^{\text {st }}$ degree heart block, $2^{\text {nd }}$ degree heart block, and left ventricular hypertrophy (LVH), each occurring in one patient. The prevalence of cardiac dysfunction was $8 \%$, with the mean of age was 12.7 (SD 7.7) years, and the mean of the serum ferritin was 4337.4 (SD 3755.1) $\mathrm{ng} / \mathrm{mL}$.

There were eight patients with systolic dysfunction, with shortening fraction below $28 \%$ and/or ejection fraction below $64 \%$. Three patients (5\%) had LV diastolic dysfunction and ten patients (16\%) had RV diastolic dysfunction. From 21 patients, three had one or more abnormalities, two patients had LV and RV diastolic dysfunctions, and one had LV systolic and diastolic dysfunctions. Based on the operational definition used in this study, the prevalence of cardiac dysfunction by echocardiography examination was $29 \%$, the mean age was 12.9 (SD 6.4) years, and the mean serum ferritin was 4074.6 (SD 2801) $\mathrm{ng} / \mathrm{mL}$.

The serum ferritin concentration correlated well with the cumulative blood volume transfusions $(\mathrm{p}=0.001, r=0.408)$ (Figure 1).

Four out of 62 patients were excluded from the analysis because they had never used DFO. Patients were then divided in to two groups. Group A with regular DFO (11 patients), mean ferritin level was 4163.2 (SD 2904.9) ng/ml. Group B (47 patients) with irregular DFO, mean ferritin level was 4255 (SD 3240.2) $\mathrm{ng} / \mathrm{mL}$ There was a difference of ferritin level 


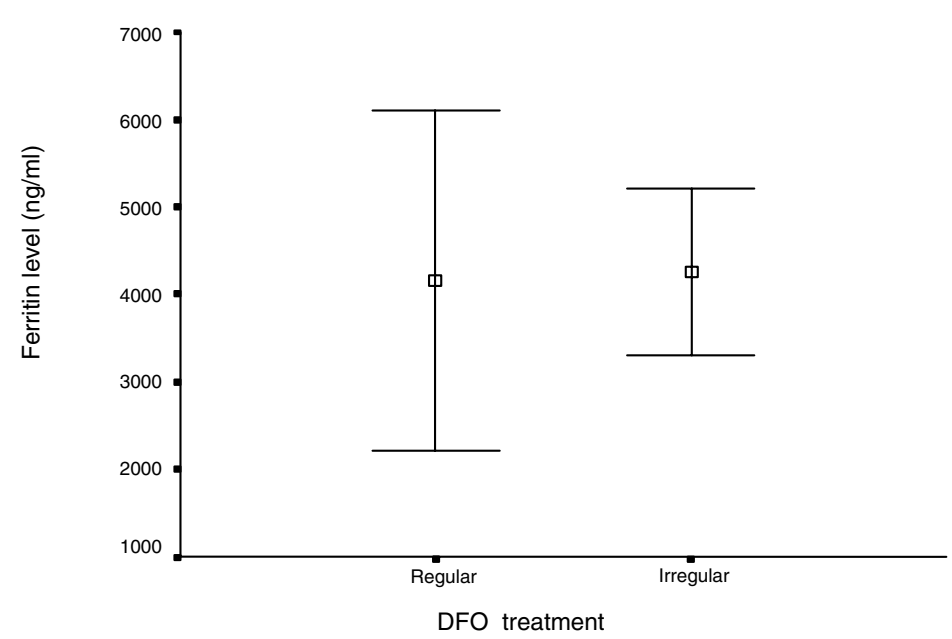

Figure 2. Correlation between serum ferritin with DFO treatment

between group $\mathrm{A}$ and $\mathrm{B}$, but it was insignificant $(\mathrm{p}=$ 0.472) (Figure 2). Predictive value and cut off point of ferritin level in cardiac dysfunction could not be determined because the area under the ROC curve was only $53 \%(\mathrm{p}=0.707)$.

\section{Discussion}

The amount of blood transfusion has not been proven to be an accurate index of iron overload, since iron turnover and iron absorption are increased and iron chelating therapy decreases the amount of deposited iron. The serum ferritin is highly correlated with the amount of iron deposited in tissue and is considered as a high sensitivity index. ${ }^{14}$ In the present study, we found a good correlation between the amount of blood transfused and the ferritin level.

The negative correlation between ferritin level and DFO therapy may be due to a preexisting high level of ferritin or disproportionate DFO dose since its initial administration. The serum ferritin level is also influenced by ferritin release from damaged cells due to inflammation, infection, liver disorder or malignancy. ${ }^{2,15}$ This study was not designed to determine these influencing factors.

Brittenham GM et al ${ }^{15}$ concluded that early administration of DFO in proportional dose, effectively reduces the body iron burden and helps protect against complications and early death in patients with thalassemia major.
Cardiac complications are the most common cause of death in patients with $\beta$-thalassemia major. The most serious complications included arrhythmias, congestive heart failure, and pericarditis. ${ }^{17}$ The pathophysiology of heart failure is unclear, although it is believed to be strongly related to the cardiac iron content and to the cumulative blood transfusion load. The three most frequent abnormal findings by ECG examination were left ventricular hypertrophy, dysrhythmia, and atrioventricular conduction delay (first and second degree of heart block). In this study, we found two dysrhythmia patients, one $1^{\text {st }}$ degree heart block patient, one $2^{\text {nd }}$ degree heart block patient, and also one left ventricular hypertrophy $(\mathrm{LVH})$ patient.

The low prevalence of cardiac dysfunction by ECG examination (8\%) in this study might be due to ECG insensitiveness in detecting cardiac dysfunction before the onset of clinically apparent disease. ${ }^{13}$ Other possibility is that most subjects were in the young age group ( $<15$ year old) leading to less possibility of cardiac involvement.

The prevalence of cardiac dysfunction by echocardiography was 29\%, lower than the finding of Olivieri et al (37\%) ${ }^{16}$; this may be due to the difference in the mean age of the subjects in this study which was 11.5 (SD 5.2) years, compared to 23 (SD 5) years in Olivier's study. The limitation of this study was that outpatients were included, while inpatients that might have severer symptoms of cardiac dysfunction were excluded. 
Anemia, as a confounding factor in this study, could not be totally excluded, but we tried to minimize this factor by performing post transfusion echocardiography. The occurrence of cardiac disorder due to severe and progressive anemia is reversible. $^{2}$

The negative correlation between ferritin level and cardiac dysfunction might be due to other causes such as myocarditis, which has a potential role in the development of congestive heart failure.

We concluded that there was no correlation between the serum ferritin levels with cardiac dysfunctions. Echocardiography examination was more sensitive than ECG in detecting cardiac dysfunction in thalassemic patient. Patients with serum ferritin level above $4000 \mathrm{ng} / \mathrm{mL}$ should undergo regular echocardiography examination to detect any possibility of cardiac dysfunctions.

\section{Acknowledgments}

The authors wish to thank Mulyadi M Djer, MD and Syarif Rohimi, MD for their help in doing the echocardiography examinations.

\section{References}

1. Spirito P, Lupi G, Melevendi C, Vecchio C. Restrictive diastolic abnormalities identified by Doppler echocardiography in patients with thalassemia major. $\mathrm{Cir}$ culation 1990; 82:88-94.

2. Weatherall DJ, Clegg JB. The $\beta$ thalassemias. In: Weatherall DJ, Clegg JB, editors. The thalassaemia syndromes. $3^{\text {rd }}$ ed. London: Blackwell scientific publications; 1981. p. 148-319.

3. Powell LW, George DK, McDonnell SM, Kowdley KV. Diagnosis of hemochromatosis. Ann Intern Med 1998;129:925-31.

4. Barton JC, McDonnell SM, Adam PC, Brissot P, Powell LW, Edwards CQ, et al. Management of hemochromatosis. Ann Intern Med 1998; 129:932-9.
5. McDonagh KT, Nenhuis AW. The thalassemias. In: Nathan DG, Oski FA, editors. Hematology of infancy and childhood. $4^{\text {th }}$ ed. Philadelphia: WB Saunders; 1993. p. 783-857.

6. Worwood M. Pathogenesis and management of haemochromatosis. Br J Haematol 1999;105: 16-8.

7. Lau KC, Li AMC, Hui PW, Yeung CY. Left ventricular function in $\beta$ thalasaemia major. Arch Dis Child 1989; 64:1046-51

8. Edwards CQ, Kushner JP. Screening for hemochromatosis. N Engl J Med 1993; 328:1616-20.

9. Pippard NE. Iron loading and chelation therapy. In: Weatherall DJ, editor. The thalassemias. New York: Churchill Livingstone; 1983. p. 103-13.

10. Garcia P. Iron in today's laboratory. Clin Biochemist Rev 1997; 18:113-7.

11. Ehlers KH, Giardina PJ, Lesser ML, Engle MA, Hilgartner MW. Prolonged survival in patients with beta-thalassemia major treated with deferoxamine. J Pediatr 1991; 118:540-5.

12. Kremastinos DT, Tsiapras DP, Tsetsos GA, Rentoukas EI, Vretou HP, Toutouzas PK. Left ventricular diastolic Doppler characteristics in b-thalassemia major. Circulation 1993; 88:1127-35.

13. Leon MB, Borer JS, Bacharach SL, Green MV, Benz EJ, Griffith P, et al. Detection of early cardiac dysfunction in patients with severe beta-thalassemia and chronic iron overload. N Engl J Med 1979; 22:1143-8.

14. Olivieri NF, Brittenham GM. Iron-chelating therapy and the treatment of thalasemia. Blood 1997; 89:739-54.

15. Brittenham GM, Griffith PM, Nienhuis AW, McLaren CE, Young NS, Tucher EE, et al. Efficacy of deferoxamine in preventing complications of iron overload in patients with thalassemia major. N Eng J Med 1994; 331:567-73.

16. Olivieri NF, Nathan DG, Mac Millan JH, Wayne AS, Liu AP, McGee A, et al. Survival in medically treated patients with homozygous b-thalassemia. N Engl J Med 1994; 331:574-8.

17. Kremastinos DT, Tiniakos G, Theodorakis GN, Katritsis DG, Toutouzas PK. Circulation 1995; 91;66-71.

18. Koren A, Garty itzhak, Antonelli D, Katzumi E. Right ventricular cardiac dysfunction. Am J Dis Child 1987; 141:93-6. 